\title{
Análise de um Livro Didático de Geometria Plana Apoiada na Hermenêutica de Profundidade
}

\author{
Analysis of a Textbook of Geometry Based on Depth Hermeneutics
}

\author{
Fernando Guedes Cury ${ }^{1}$
}

\begin{abstract}
Resumo
O artigo apresenta resultados da análise de um livro muito usado no ensino de Geometria em cursos de Matemática no Brasil: Elementos de Geometria Plana, de João Lucas Barbosa. Nossos esforços foram direcionados pelas questões: como são organizados/estruturados os livros de Geometria Euclidiana, mais comuns, na formação de professores de matemática? e que tipo de tarefas são propostas aos seus leitores? Para tanto, valemo-nos da Hermenêutica de Profundidade como metodologia de investigação por compreendermos que o livro didático é uma "forma simbólica" (produção intencional humana). O estudo contemplou uma investigação do contexto do período de produção e de circulação da primeira edição da obra e de uma análise de sua estrutura, com destaque para uma classificação das tarefas ali propostas. Percebemos fortes laços da obra com ideias características do Movimento da Matemática Moderna, como a supervalorização do ensino pautado na construção lógico-dedutiva, notadamente, pela grande proposição de exercícios voltadas a demonstrações.
\end{abstract}

Palavras-chave: Ensino de Geometria; Livro Didático; Hermenêutica de Profundidade; Classificação de Problemas; Formalismo.

\begin{abstract}
The paper presents results of the analysis of a Geometry textbook too much used in Math teacher's edication in Brazil called Elementos de Geometria Plana, written by João Lucas Barbosa. We were guided by the follow questions: how are the most common Euclidean geometry books organized / structured in the training of mathematics teachers? and what kind of tasks are proposed to your readers? For this, we use the Depth Hermeneutics as research methodology because we understand that the textbook is a "symbolic form" (human intentional production). The study contemplated an investigation of the context of the production and circulation period of the first edition of that book and an analysis of its structure, with emphasis on a classification of the tasks proposed there. We perceive strong ties of the book with ideas characteristic of the Modern Mathematics Movement, such as the overvaluation of the teaching based on the logical-deductive construction, notably, the great proposition of exercises directed to proofs of conjectures.
\end{abstract}

Palavras-chave: Teaching of Geometry; Textbook; Hermeneutics of Depth; Classification of Problems; Formalism.

\footnotetext{
Submetido em: 14/12/2018 - Aceito em: 15/05/2019 - Publicado em: 28/05/2019

${ }^{1}$ Doutor em Educação Matemática pela Universidade Estadual Paulista (Rio Claro). Professor da Universidade Federal do Rio Grande do Norte (Natal/Brasil). E-mail: matfernando@yahoo.com.br.
} 


\section{Introdução}

O livro didático (textbook, livro-texto ou manual escolar) é, entre todos os materiais voltados ao planejamento e desenvolvimento de atividades educativas, aquele com o maior uso, tanto por estudantes quanto por educadores. Seu estudo permite detectar ênfases e omissões em relação aos currículos oficiais e é uma referência de estudo para os professores que nele revisaram o que devem ensinar (Marmolejo, 2014). Além disso, livros didáticos podem evidenciar quais os conteúdos estão presentes (ou não) no cotidiano da matemática escolar (Valente, 2008) e, ainda, indicar o surgimento/desaparecimento de conceitos e de abordagens didáticas (Sierra, González e López, 1999).

No caso dos livros didáticos antigos, pode-se dizer que suas análises são ainda mais significativas para a compreensão de determinada cultura escolar dada a influência deles sobre as ações docentes em períodos e lugares com pouca disponibilidade de recursos para os professores que atuaram antes da expansão do ensino e que tinham uma formação limitada. Segundo Schubring (2003), o interesse acadêmico pelos textbooks tem início após a repercussão da obra de Thomas Kuhn, "A Estrutura das Revoluções Científicas”, de 1962. Ele diz que Kuhn via esses materiais como um elemento de distinção entre "conhecimento escolar" e "conhecimento científico", uma introdução ao paradigma da ciência "normal".

O livro didático constitui-se, portanto, em uma fonte importantíssima para a história de uma disciplina escolar ao simbolizar uma construção cultural, ao estruturar um "conhecimento", ser uma das mais presentes materializações da relação pedagógica e, ainda, configurar o campo epistêmico e pedagógico de uma cultura escolar (Magalhães, 2006). O estudo do livro didático como uma faceta da pesquisa em História da Educação Matemática (HEM) permite, como dizem Vidal e Faria Filho (2005), desnaturalizar ideias, alargar horizontes, rememorar, memorizar, determinar projetos silenciados, entender as razões pelas quais o passado se desenrolou neste nosso presente e não outro, viajar, ir ao encontro do outro, aprender, ensinar... Além de outras possibilidades permitidas pela reflexão historiográfica.

Atentos à importância dos livros didáticos tanto para educação básica quanto ao ensino superior, em especial, na formação de professores, voltamos nossa atenção para um estudo sobre livros de Geometria Euclidiana Plana na licenciatura em Matemática brasileira. Identificando as principais obras e, para uma delas, fizemos um estudo (que destacou o contexto de sua idealização e circulação) além de uma descrição de sua estrutura, com destaque a uma classificação dos exercícios/problemas propostos. Nossos esforços foram direcionados por questões como: como são organizados/estruturados os livros de Geometria Euclidiana voltados à formação de professores de matemática no Brasil? Que tipo de formação estes materiais propiciam a seus leitores? Que tipo de tarefas eram propostas? E para responder essas perguntas definimos alguns objetivos: identificar as principais obras voltadas ao ensino de Geometria em cursos de formação de professores; 
DOI: 10.20396/zet.v27i0.8654251

mobilizar a Hermenêutica de Profundidade como estratégia metodológica para analisar o livro mais usado; realizar uma classificação dos problemas/exercícios presentes na obra selecionada inspirada em Borasi (1986).

Nossa análise foi feita segundo a Hermenêutica de Profundidade (HP) que se baseia, sumariamente, em uma análise sócio-histórica e em uma análise formal. Para a segunda dessas modalidades, optamos, além da descrição da estrutura do livro, por uma classificação de problemas matemáticos. O presente texto dedica-se, então, a ensaios que refletem nossas análises.

Escolhemos a HP como estratégia metodológica por compreendermos que o livro didático de Matemática pode ser considerado uma "forma simbólica", isto é, o fruto da produção intencional humana e produzido de acordo com uma estrutura convenientemente articulada. E justificamos a avaliação das atividades propostas no livro didático observado, pois a resolução das tarefas matemáticas envolve diferentes conhecimentos e habilidades e estabelecer as diferenças entre elas podem, no mínimo, nos ajudar a compreender o que autores esperam de seus leitores e o que os docentes que fazem uso do livro esperam de seus alunos. Além disso, acreditamos que os exercícios e problemas propostos na obra destacam funções instrucionais do livro didático (ao propor métodos, exercícios e atividades que visam a facilitar a aprendizagem), podendo indicar seu papel curricular de suporte de conteúdos e, também, apresentar caráteres ideológicos e culturais de seu(s) autor(es) e do contexto ao qual se insere.

\section{Procedimentos de investigação e de análise}

Inicialmente desejávamos fazer o levantamento e estudo dos livros que usados ao longo dos anos para o ensino de Geometria Euclidiana no Curso de Licenciatura em Matemática (presencial) onde atuamos $-\mathrm{UFRN}^{2}$. Porém, como não encontramos referências aos os livros/manuais didáticos usados nas primeiras décadas do curso para serem analisados voltamos nosso foco aos livros que, pelo menos mais recentemente, tivessem sido largamente utilizados no Brasil. Fizemos, então, uma catalogação dos livros de Geometria citados nos Projetos Pedagógicos de Curso (PPCs) dos cursos de licenciatura em Matemática, disponíveis na internet que tiveram nota superior a três no Exame Nacional de Desempenho dos Estudantes (ENADE) do ano de 2011. Os PPCs continham as ementas das disciplinas de um determinado curso e, geralmente, apresentavam uma lista de livros indicados como referência básica ou complementar para as aulas. Os PPCs com as características citadas acima foram usados na pesquisa de Rodrigues, Silva e Ferreira $(2016){ }^{3}$ e foram gentilmente cedidos a nós

\footnotetext{
${ }^{2}$ Parte desta pesquisa foi realizada com Bolsa de Iniciação Científica concedida pelo Conselho Nacional de Desenvolvimento Científico e Tecnológico (CNPq).

${ }^{3} \mathrm{Na}$ pesquisa, esses autores buscaram identificar quais eram os textos/livros "clássicos" usados em cursos de matemática no Brasil. Dos 415 cursos identificados no Portal do Instituto Nacional de Estudos e Pesquisas 


\section{DOI: 10.20396/zet.v27i0.8654251}

por aqueles pesquisadores. A contagem dos mostrou que o livro de Geometria mais citado nos 180 PPCs observados foi "Geometria Euclidiana Plana", de João Lucas Marques Barbosa, publicada pela Sociedade Brasileira de Matemática (SBM): apareceu 96 vezes. Em segundo lugar, o livro da Coleção Fundamentos da Matemática Elementar, volume 9, de autoria de Oswaldo Dolce e José Nicolau Pompeo, citado 69 vezes. $^{4}$

Estamos cientes de que, embora esses livros tenham sido referenciados um determinado número de vezes, isso não implica em seu uso efetivo ou regular nas aulas, porém, ao menos indica que existem intenções dos autores daqueles documentos e dos que dirigem as disciplinas de Geometria em cursos de graduação em usá-los. Optamos, então, por focar na primeira edição da obra de Barbosa, datada de 1985, que foi adquirida em uma loja virtual de livros usados.

Após essa fase inicial, realizamos um estudo histórico do livro apoiados na Hermenêutica de Profundidade (HP), um referencial para se analisar "formas simbólicas" criadas e difundidas por esses meios de comunicação. De maneira simplificada podemos dizer que as formas simbólicas são produtos (ou expressões) produzidos por um sujeito endereçado a outro sujeito.

O desenvolvimento dessa metodologia dá-se, segundo Thompson (2011), em três etapas: análise sócio-histórica, análise formal (ou discursiva) e interpretação/reinterpretação. $\mathrm{Na}$ primeira delas, busca-se reconstruir as condições sociais e históricas de produção, circulação e recepção das formas simbólicas, considerando as relações de dominação que caracterizam aquele contexto. Os objetivos dessa etapa podem ser resumidos em: (a) identificar e descrever as situações espaço-temporais em que as formas simbólicas são produzidas e recebidas; (b) analisar o campo de interação das formas simbólicas: trajetórias que determinam como as pessoas têm acesso às oportunidades de usar as formas simbólicas emprego dos recursos disponíveis, esquemas tácitos de conduta, convenções, conhecimento próprio inculcado nas atividades cotidianas; (c) analisar as instituições sociais, isto é, as regras e os recursos em uso nas relações sociais e examinar as práticas e as atitudes das pessoas que agem a favor delas; (d) analisar as estruturas sociais: estabelecer critérios e categorias para examinar as diferenças da vida social; e (e) examinar os meios técnicos de constituição de mensagens e como eles são inseridos na sociedade.

A segunda etapa é o momento em que o foco do exercício analítico é o "objeto de estudo em si", e em nosso caso, o livro didático. Esse é o momento de olhar para a composição da forma simbólica e como ela se constitui como uma estrutura articulada. Segundo Thompson (2011), dependendo dos objetos e circunstâncias particulares da

Anísio Teixeira (INEP) em 2013 - ano daquela coleta de dados - foram selecionados para a análise os PPCs dos 86 cursos que tinham, à época, avaliação 4 ou 5 segundo o Exame Nacional de Cursos (ENADE). Os autores gentilmente nos facultaram o acesso a 180 PPCs.

${ }^{4}$ Em nossa contagem, quando havia mais de uma disciplina dedicada à Geometria num curso, contabilizávamos as referências disponíveis em todas elas. Assim, mesmo que em um curso houvesse uma disciplina dedicada a uma abordagem mais axiomática da Geometria ou numa perspectiva de revisar Geometria da escola básica (e que não representou um número significativo de cursos), levamos em conta apenas a referência ou não às obras. 


\section{DOI: 10.20396/zet.v27i0.8654251}

investigação, há várias formas para conduzir essa fase, como, por exemplo, análise semiótica, análise sintática, análise narrativa, análise argumentativa, análise de conversação.

A terceira etapa da HP, chamada de interpretação/reinterpretação, deve ser construída a partir dos resultados da análise sócio-histórica e da análise formal-discursiva, tendo seu foco de interesses sobre a "explicitação [...] do que é dito ou representado pela forma simbólica” (Thompson, 2011, p. 34). Busca-se nesta fase entender o que foi dito por meio das formas simbólicas e como as relações de poder que foram sustentadas por elas, ou seja, tentase desvendar a ideologia por trás daquela forma simbólica. A importância de se concentrar em vários aspectos da forma simbólica dá-se porque, segundo aquele autor, as ela reforça e transmite uma ideologia a partir de diferentes mecanismos. ${ }^{5}$

Para a execução da fase da HP (análise formal), optamos - além de uma descrição estrutural da obra - por recorrer a um método de classificação dos exercícios/problemas apresentadas como tarefa aos leitores da obra. Fizemos por uma adaptação da tipologia usada por Borasi (1986) que classificava as tarefas matemáticas em: exercício, problema com texto, puzzle (quebra-cabeça), prova de uma conjectura, problemas da vida real, situações problemáticas e situações. Optamos por uma adaptação e reunimos na categoria problemas o que Borasi classificava como problemas com texto e problemas da vida real e, além disso, a tipologia daquele autor não tinha uma categoria compatível com o que chamamos de construção e que abarcaria um número relevante de tarefas na obra estudada. ${ }^{6}$ Os tipos de exercícios que usamos para classificar os que apareciam na obra que analisamos foram, portanto, os seguintes:

- Exercício: tarefas ou atividades que pretendem desenvolver algum tipo de algoritmo nas quais se aplicam conhecimentos de forma imediata, ou seja, não é necessário buscar uma combinação adequada destes algoritmos, descrevendo uma situação do mundo real (mesmo que hipotética) ou não.

- Problemas: são as atividades cujo contexto pode ser matemático, ou seja, com atividades típicas da sala de aula da matemática, mas que, ao contrário dos exercícios, exigem uma combinação de estágios intermediários ou desconhecidos para alcançar a solução que não é indicada no enunciado. A resposta não se obtém imediatamente aplicando uma fórmula, algoritmo ou cálculo que é indicado no enunciado. Podem ser elaborados com situações reais, que não estão preparados para serem resolvidos em sala de aula.

\footnotetext{
${ }^{5}$ Alguns exemplos de Como a HP pode contribuir com pesquisas em História da Educação Matemática podem ser vistos em Souza, e Cury (2015) e em Garnica e Salandim (2014).

${ }^{6}$ Outras tipologias para classificação de atividades matemáticas podem ser envontradas em Conejo e Ortega (2013).
} 


\section{DOI: 10.20396/zet.v27i0.8654251}

- Puzzles (quebra-cabeças): esse tipo de tarefa é diferente das outras, pois o contexto e a formulação, apesar de ser explícitos e conterem todas as informações contidas no enunciado, são enganosas ou, de certo modo, enganosas.

- Prova de conjectura: envolve a exploração de um contexto com a elaboração de algoritmos ou de um discurso que visa tornar inteligível o caráter de verdade de uma proposição ou de um resultado. Embora o contexto e a formulação destas tarefas sejam completamente dados no enunciado, pode ser necessário usar outros teoremas ou resultados matemáticos que não são indicados.

- Situações: neste tipo de problema, o estudante enfrenta um novo resultado matemático sem que tenha todas as informações necessárias. Normalmente, é uma situação que aumenta uma questão aberta sobre certa propriedade matemática. Espera-se do resolvedor a formulação de conjecturas pelo aluno. Neles se apresentam certos fatos ou propriedades matemáticas que exigem a reflexão dos estudantes com o propósito de estabelecer novas relações ou propriedades em relação com as informações fornecidas pela situação. Não há pergunta específica ou um slogan sobre o que o aluno tem que fazer.

- Construção: são atividades que solicitam, do ao resolvedor, a descrição de uma sequência de procedimentos necessária para resolver um exercício/problema ou para a construção de uma estrutura (geométrica), a partir de objetos matemáticos dados.

Destacamos que nossa escolha pelo uso da classificação de problemas como uma estratégia para nossa análise apoia-se em dois aspectos: primeiramente no fato que, segundo o próprio Thompson (2011), a HP não deve ser entendido como uma estratégia que exaure todas as possibilidades de produção de significados a uma forma simbólica - ele próprio comenta, como dissemos alguns parágrafos acima, que há diferentes maneiras de abordagem na etapa da "analise interna". Em segundo lugar, a forma simbólica a ser analisada, por ser um livro didático de Matemática, tem em sua composição uma extensa quantidade de exercícios/atividades que são, por vezes, considerados pontos altos do fazer matemático e do seu ensino. Dante (1988), por exemplo, ao defender a resolução de problemas como estratégia pedagógica, disse que resolver problemas permite que o aluno pense produtivamente, desenvolva o seu raciocínio, prepare-o para enfrentar situações novas possibilitando uma boa alfabetização matemática ao cidadão comum. A resolução das tarefas matemáticas envolve diferentes conhecimentos e as habilidades que permitem estabelecer diferenças entre elas. A princípio podemos identificar uma diferença geral entre problema e exercício: estes aparecem para reconhecer ou praticar algum procedimento algébrico ou aritmético habitual, mas a forma de apresentá-los pode exigir diferentes ações para resolvê-lo. Da mesma forma, os contextos ou recursos e as ações exigidas para resolvê-los permite estabelecer diferenças entre eles (Pinos Ceballos, 2015). 
DOI: $10.20396 /$ zet.v27i0.8654251

Salientamos, ainda, que durante nossos estudos entramos em contato com o professor João Lucas Marques Barbosa por telefone e por correio eletrônico solicitando sua ajuda na pesquisa que estávamos desenvolvendo que tinha seu livro como peça central. Ele concordou em colaborar respondendo, por e-mail, um questionário sobre sua carreira, atuação na SBM e, principalmente, sobre a produção do seu livro. Nas seções seguintes sistematizamos algumas compreensões e respostas às questões que dirigiram nosso estudo em função das escolhas metodológicas descritas acima. Para esclarecer os nossos leitores, quando fizermos referências a informações obtidas pelo contato direto com o autor da obra analisada, usaremos seus primeiros nomes (João Lucas) e quando nos referirmos a informações oriundas da análise de seu livro, faremos referências do tipo "Barbosa (2012)".

\title{
Um pano de fundo para a produção da obra estudada: o ensino de Geometria no Brasil dos anos 1980
}

O ensino no Brasil e em outros países foi influenciado por diretrizes que buscavam aproximar a Matemática escolar de uma matemática mais abstrata, tal como a produzida pelos pesquisadores universitários. O ensino de Geometria, particularmente, deveria ser feito via transformações geométricas, pois esta abordagem possibilitaria seu tratamento a partir das estruturas algébricas. Um dos defensores dessas propostas em nosso país, Benedito Castrucci (1909-1995), explicou como isso deveria acontecer:

\begin{abstract}
/.../ se nós estamos fazendo um movimento em que tudo tinha que nascer da teoria dos conjuntos e da idéia de estrutura, que era um princípio geral /.../ a única coisa que a gente podia dizer em geometria é que o plano é um conjunto de pontos, o espaço é um conjunto de pontos, a reta é um sub-conjunto do plano, mas depois como é que eu vou dizer, axiomas, teoremas, tudo o mais? /.../ Então o processo foi sair uma geometria também por meio de uma estrutura algébrica. Daí fizeram o estudo de geometria já no ginásio por meio de espaços vetoriais, que é uma estrutura algébrica. /.../ E outro caminho foi pelos grupos de transformações... (Castrucci, citado por Duarte \& Silva, 2006, p. 90).
\end{abstract}

Segundo Pavanello (1993), os primeiros livros que atendiam as indicações do Movimento da Matemática Moderna (MMM), que teve seu auge no Brasil nos anos 1960 e 1970, não se preocupavam com a construção de uma sistematização a partir de noções primitivas empiricamente elaboradas. Uma abordagem "intuitiva" era usada com o uso dos teoremas como postulados a partir dos quais se poderiam resolver alguns problemas. Mas a autora salienta que o ensino de Geometria na abordagem tradicional já era problemático em relação ao baixo conhecimento do professor, aos métodos usados, à dificuldade de relacionar a teoria e a prática - e o enfoque das transformações trouxe, na verdade, problemas ainda maiores. Essa situação fez com que muitos professores passassem a não ensinar Geometria por nenhum dos enfoques, uma omissão que acabou amparada, por assim dizer, pela Lei de Diretrizes e Bases do ensino de $1^{\circ}$ e $2^{\circ}$ Graus, lei n ${ }^{\circ} 5692 / 71$ :

\footnotetext{
A liberdade que essa lei concedia às escolas quanto à decisão sobre programas das diferentes disciplinas sobre os programas das diferentes disciplinas possibilitou que muitos professores de matemática, sentindo-se inseguros para trabalhar com a geometria, deixassem de incluí-la em sua programação. Por outro lado, mesmo dentre aqueles que continuaram a ensiná-la,
} 
DOI: $10.20396 /$ zet.v27i0.8654251

muitos reservaram o final do ano letivo para sua abordagem em sala de aula- talvez numa tentativa, ainda que inconsciente, de utilizar a falta de tempo como desculpa pela não realização do trabalho programado com o tópico em questão (Pavanello, 1993, p.7).

O tratamento da Geometria com formalização precoce de conceitos, memorização de procedimentos sem sua devida compreensão ou até a completa omissão do seu ensino, não ficou restrito à educação básica no período de 1950 a 1970. Pode-se dizer que um ciclo foi criado, no qual os alunos das escolas não tiveram acesso aos conteúdos de Geometria e, chegando a cursos de graduação em Matemática, essa carência passou despercebida palas instituições formadoras - talvez por considerarem que os futuros professores já dominassem aqueles conceitos. Mesmo em fins do século passado, Gazire (citada por Crescenti, 2005) indicava que os professores que não gostavam de ensinar Geometria, "aprenderam pouco ou nada de Geometria nos cursos de Licenciatura" e tinham "medo de ensinar Geometria" (p. 39).

A formação de professores de Matemática no Brasil dos anos 1980, época do lançamento do livro Elementos de Geometria Plana (Barbosa, 1985), por sua vez, era resultado direto de transformações das décadas anteriores. A Lei $n^{\circ} 4.024$, de 20 de dezembro de 1961, primeira Lei de Diretrizes e Bases da Educação Nacional, criou o Conselho Federal de Educação (CFE) e delegou a ele, entre outras competências, a fixação dos conteúdos mínimos e a determinação da duração dos cursos superiores voltados a formar agentes para as profissões regulamentadas em lei, entre eles, a licenciatura em Matemática. A partir do Parecer 295 de 14 de novembro de 1962, o CFE apontou que a licenciatura deveria ser oferecia como um curso único de quatro anos em que formação pedagógica ocorreria simultaneamente com outras disciplinas, com o consequente fim da obrigatoriedade de se fazer um curso de bacharelado e uma formação complementar para ser professor (Junqueira \& Manrique, 2015). Esse parecer também determinou que o currículo mínimo da licenciatura abrangesse as seguintes disciplinas: "Desenho Geométrico e Geometria Descritiva, Fundamentos da Matemática Elementar, Física Geral, Cálculo Diferencial e Integral, Geometria Analítica, Álgebra e Cálculo Numérico" (Idem, p. 626, negritos nossos), além das disciplinas de cunho pedagógico. O documento ainda mostra que, para a disciplina de Fundamentos da Matemática Elementar, era "sugerida uma análise e revisão dos assuntos lecionados nos, então, cursos ginasial e colegial, tendo em vista o aprofundamento desses assuntos" (Idem). Mas tal indicativo, por tudo que foi dito no parágrafo anterior, não parece ter se efetivado.

Um pouco mais tarde, a Lei $\mathrm{n}^{\mathrm{o}} 5.540 / 68$, conhecida como Lei da Reforma Universitária, teve a finalidade de modernizar a universidade brasileira que estava em expansão à época da sua promulgação. Mas, segundo Junqueira e Manrique (2015), a universidade, "em seu cerne, permaneceu com a mesma estrutura anacrônica, como um entrave ao processo de desenvolvimento" (p. 626) e a Reforma ainda trouxe algumas consequências negativas como, por exemplo, a fragmentação do trabalho docente, o isolamento de pesquisadores e a dispersão de alunos pelo sistema de créditos. No caso do 
DOI: $10.20396 /$ zet.v27i0.8654251

licenciado em Matemática, a formação permitia, na época, ministrar aulas de Matemática, Física, Desenho e/ou Ciências, nos ensinos de $1^{\circ}$ e $2^{\circ}$ graus (hoje equivalentes ao atual Ensino Fundamental e Ensino Médio, respectivamente). A Reforma Universitária e a Lei 5692/71 (que reestruturou o ensino básico) possibilitaram ainda o surgimento das "licenciaturas curtas", cursos mais aligeirados (cerca de 1200 horas) para a formação de docentes, mas que foram extintos pela atual Lei de Diretrizes e Bases da Educação (n ${ }^{\circ}$ 9.394/96). Aliás, a formação de professores ficou subordinada àquelas regulamentações dos anos 1960 e 1970 até o final do século XX.

Muitas críticas foram direcionadas às diretrizes do MMM para o ensino de Matemática dos anos 1970 e início dos 1980. A obra do estadunidense Morris Kline intitulada O Fracasso da Matemática Moderna, por exemplo, fez críticas ao exagero da forma dedutiva de se abordar os conteúdos e ao excessivo formalismo e simbolismo da linguagem, porque não eram adequados para os níveis elementares, confundindo os alunos e estimulando sua aversão pela matemática (Pinto, 2006). Apesar dessas críticas voltarem-se ao ensino norte-americano, elas tinham sentido no contexto brasileiro, pois por aqui a abordagem tecnicista dominava as práticas escolares daquele período.

[...] o livro de Kline, apesar de publicado no Brasil três anos após sua divulgação nos Estados Unidos, foi um marco decisivo para o esgotamento do movimento em nosso país. As críticas não vinham apenas dos meios acadêmicos: pais de alunos e também a imprensa denunciavam as superficialidades da simbologia da matemática moderna e o tempo 'perdido' com o ensino da teoria dos conjuntos. Admitindo a confusão que a linguagem dos conjuntos provocava nos alunos e o baixo rendimento por eles demonstrado, os professores mostravam sua insatisfação com a proposta (Soares apud Pinto, 2006, p. 4063).

Osvaldo Sangiorgi, um dos educadores que difundiram as ideias modernizadoras no Brasil, também chegou a reconhecer que a abordagem escolhida naquele período não favorecia a aprendizagem da geometria ao apontar, em um artigo de jornal, no ano de 1975, os principais efeitos da Matemática Moderna no Ensino:

1. Abandono paulatino do salutar hábito de calcular (não sabendo mais a 'tabuada' em plena $5^{\text {a }}$ e $6^{\mathrm{a}}$ séries!) porque as operações sobre conjuntos (principalmente com os vazios!) prevalecem acima de tudo; acrescenta-se ainda o exclusivo e prematuro uso das maquininhas de calcular, que se tornaram populares do mesmo modo que brinquedos eletrônicos.

2. Deixa-se de aprender frações ordinárias e sistema métrico decimal - de grande importância para toda a vida - para se aprender, na maioria das vezes incorretamente, a teoria dos conjuntos, que é extremamente abstrata para a idade que se encontra o aluno.

3. Não se sabe mais calcular áreas de figuras geométricas planas muito menos dos corpos sólidos que nos cercam, em troca da exibição de rico vocabulário de efeito exterior, como por exemplo 'transformações geométricas'.

4. Não se resolvem mais problemas elementares - da vida quotidiana - por causa da invasão de novos símbolos e de abstrações complementarmente fora da realidade, como: 'O conjunto das partes de um conjunto vazio é um conjunto vazio?', proposto em livro de $5^{\text {a }}$ série (Sangiorgi, 1975b apud Pinto, 2006, 4064, negritos nossos).

Com tantas reações contra o MMM, iniciaram-se, nos idos de 1980, discussões com a proposta de conceber a Matemática como uma linguagem que permitisse compreender os 
DOI: 10.20396/zet.v27i0.8654251

fenômenos à nossa volta, e de seu ensino valorizar as diferentes formas de representação dos elementos matemáticos, considerando os conhecimentos prévios dos estudantes e detectando seus interesses e suas "realidades particulares". ${ }^{7}$ Essas discussões tornam-se recorrentes em congressos, nos programas de pós-graduação e nas pesquisas, e em grupos de estudos e formação de professores. É nesse contexto, no ano de 1985, que a obra Geometria Euclidiana Plana foi publicada.

\section{Um olhar para a "Geometria Euclidiana Plana" de João Lucas Marques Barbosa}

João Lucas Marques Barbosa, natural de Fortaleza/CE, completou em 2018 seus 75 anos e foi estudante da primeira turma do curso de Matemática da Universidade Federal do Ceará (UFC) que formou cinco alunos em 1965. Naquela época era comum que esses estudantes assumissem postos de ensino nas instituições em que se formaram. Com ele não foi diferente: ingressou na UFC no mesmo ano em que se formou. Professor Emérito daquela instituição, também chegou ao posto de Titular e aposentou-se em 2012. ${ }^{8}$ Seu curso de graduação se preocupava fundamentalmente com a formação de matemáticos e de professores para a Universidade, sem muita atenão à formação de profissionais para ensino básico. Ele mesmo chegou a lecionar em algumas turmas do curso de licenciatura, inclusive na chamada "licenciatura curta", que também fora criada na UFC e contou com sua colaboração para ser estruturada. Durante essas experiências na formação de professores, João Lucas observou que a maioria daqueles estudantes havia feito a escolha no vestibular para outros cursos, mas como não foram selecionados, aceitavam a oferta da UFC de participarem da licenciatura curta. Dessa forma, a evasão era muito grande. Isto o inspirou a transformar as primeiras aulas do curso em um fórum para discutir os objetivos dos vários cursos da UFC e fazer uma espécie de aconselhamento aos alunos. Com isso, ele conseguia que um grupo maior de estudantes decidisse seguir na licenciatura. E foi ao longo da sua participação em cursos como esse que ele iniciou a redação do livro Geometria Euclidiana Plana, com o propósito de oferecer notas de aula para seus alunos. Posteriormente, o texto foi submetido à apreciação da Sociedade Brasileira de Matemática para ser publicado como parte da Coleção Fundamentos da Matemática Elementar. ${ }^{9}$

\footnotetext{
${ }^{7}$ Podemos dizer que nessa época se iniciam propostas que dão destaque para o tratamento de informações, para se ensinar a resolver problemas e para o uso de tecnologias e materiais manipulativos concretos antes de ascender a raciocínios mais abstratos (Cury, 2017).

${ }^{8}$ Atualmente ele atua como presidente da Comissão de Ética da UFC e continua produzindo pesquisa nas áreas de Geometria e Topologia.

${ }^{9}$ A redação desse parágrafo, assim como ocorrerá com outros trechos a diante, está baseada no questionário respondido pelo professor João Lucas Marques Barbosa em fevereiro de 2018. Para que o leitor saiba que as informações referem-se a esse documento mencionaremos o nome completo do autor ou apenas seus dois primeiros nomes - quando as informações forem retiradas do livro, faremos a citação tradicional com o uso do último sobrenome e a data da publicação da obra.
} 
DOI: 10.20396/zet.v27i0.8654251

A Sociedade Brasileira de Matemática (SBM), fundada em 1969, atualmente tem sua sede no Instituto de Matemática Pura e Aplicada (IMPA), na cidade do Rio de Janeiro. Em agosto de 1981 ela definiu como composição da Comissão Editorial da recém-criada coleção de livros que chamou de Fundamentos da Matemática Elementar, David Goldstein Costa (coordenador), Adilson Gonçalves e o próprio Joao Lucas Marques Barbosa. Foi assim que a SBM apresentou ao público a coleção que já surgiu com quatro títulos:

[...] a Sociedade Brasileira de Matemática criou uma coleção de pequenos livros, contendo exposições sobre certos temas clássicos da Matemática que é ensinada nas escolas (principalmente os que são estudados no segundo grau) ou os que, embora não pertençam ao currículo atual, estão ao alcance do entendimento dos alunos e professores nesse nível. Nos livros dessa coleção, os assuntos, mesmo tradicionais, são abordados de modo não comumente encontrados nos textos usuais. Eles devem, de preferência, retratar a maneira como um matemático não participante do dia-a-dia da escola secundária, enxerga esses tópicos e os apresenta de modo elementar.

A fim de dar início imediatamente à coleção e, ao mesmo tempo, definir mediante exemplos concretos, o teor dos livros desejados, os quatro primeiros títulos publicados são reimpressões de monografias que, em passado recente foram bem aceitas mas se achavam esgotadas. Assim, a coleção Fundamentos de Matemática Elementar conta, até e agora, com os seguintes títulos:

1. Trigonometria e Números Complexos

por Manfredo Perdigão do Carmo

2. Áreas e Volumes

por Elon Lages de Lima

3. Logaritmos

por Elon Lages de Lima

4. Números Irracionais e Transcedentes

por Djairo G. de Figueiredo (SBM, citado por Santos, 2016, p. 173-174, itálicos do autor).

Outros títulos foram publicados foram: Episódios da História Antiga da Matemática, em 1984, de Asger Aaboe; Números Racionais e Irracionais, em 1985, de Ivan Niven, e, no segundo semestre de 1985, o Geometria Euclidiana Plana. A SBM deu destaque, à época desta última publicação, às qualificações do seu autor, salientando sua posição de professor Titular na UFC, além de membro consultor da Academia Brasileira de Ciências. Sobre este livro de Geometria, a Sociedade também destacou em um boletim informativo que, tal como os demais títulos da Coleção, aquele tinha uma linguagem clara e acessível, "inclusive a alunos", de forma que o texto deveria servir de referência básica para uma disciplina de Geometria em cursos de licenciatura em Matemática (Santos, 2016). ${ }^{10}$

\footnotetext{
10 Atualmente, as sete obras listadas acima e mais 26 da SBM encontram-se alocadas na série de livros denominada Coleção do Professor de Matemática. A mudança do nome deve-se, provavelmente, à designação Fundamentos de Matemática Elementar também ser usada pela Editora Atual, desde a década de 1970, para outra coleção de livros-texto de Matemática com vários títulos, entre eles, Conjuntos e Funções, Logaritmos, Geometria Analítica, Geometria Plana, Geometria Espacial e Trigonometria.
} 
DOI: $10.20396 /$ zet.v27i0.8654251

$\mathrm{Na}$ capa da obra analisada, além do destaque ao título, no canto superior esquerdo, logo acima do nome do autor, encontram-se, em letras menores, o nome da Coleção (no alto, à direita) e o nome da Sociedade Brasileira de Matemática (na parte de baixo, à esquerda). Como ilustração aparecem dois quadrados subdivididos em quadrados menores (em azul turquesa) e triângulos (em rosa escuro) em uma alusão a uma das maneiras de se demonstrar o Teorema de Pitágoras: pela comparação de áreas. Essa construção, aliás, é sugerida como atividade ao final do último capítulo, denominado "Área". A folha de rosto tem os mesmos elementos da capa, excetuando-se o nome da Coleção e acrescentando a palavra "por" entre o título e o nome do autor e as indicações de onde e quando a obra foi publicada (Rio de Janeiro, 1985) logo abaixo da expressão Sociedade Brasileira de Matemática. Acima da Ficha Catalográfica, uma dedicatória à mãe do autor do livro: "A Aida Marques Barbosa, que me criou incentivando o ideal pelo magistério". Abaixo da Ficha, a informação de que a publicação foi financiada pelo FINEP (Financiadora de Estudos e Projetos ${ }^{11}$ ).

Como é comum a obras que pertencem a uma coleção, o livro tem uma nota emitida pelo coordenador desta, nesse caso intitulada "Uma palavra da SBM", e assinada por Geraldo Ávila, presidente da Sociedade em 1985. O pequeno texto indica que aquele era o sétimo livro da Coleção, diz esperar que novos títulos sejam publicados, posto que eles são muito importantes para a formação do professor da escola básica, e termina agradecendo a contribuição do autor daquela obra. O segundo parágrafo dessa nota é interessante por mostrar que a SBM estava atenta ao modo como vinha sendo conduzido o ensino de Geometria no Brasil:

\begin{abstract}
O presente livro versa sobre tema que há muito vem sendo relegado no ensino elementar. Esse quase abandono da Geometria nas escolas de $1^{\circ}$ e $2^{\circ}$ graus constitui-se em falha muito grave no ensino de Matemática. O livro de Geometria Euclidiana Plana, ora lançado na Coleção Fundamentos, é certamente um esforço promissor e muito oportuno no sentido de contribuir pera corrigir a referida falha do ensino de Matemática em nosso país. (Barbosa, 1985, não paginado)
\end{abstract}

A lista de conteúdos do livro é precedida por uma página destinada a apresentar todos os títulos daquela Coleção à época, destacando a qualificação dos autores e apontando que os textos tratam de assuntos que pertencem ao currículo escolar ou que são importantes para bem informar o professor, estudantes ou até amadores da Matemática. Nesta espécie de propaganda também são indicados os valores dos exemplares, adquiridos apenas diretamente com a SBM - assim como ainda é feito atualmente. O preço indicado para o livro de Geometria foi corrigido de Cr\$18.000,00 para Cr\$24.000,00 para vendas entre outubro e dezembro daquele ano.

\footnotetext{
11 Empresa pública criada em 1967 e hoje vinculada ao Ministério da Ciência, Tecnologia e Inovação, cuja missão é promover o fomento à ciência, tecnologia e inovação em empresas, universidades, institutos tecnológicos e outras instituições públicas ou privadas.
} 
As 190 páginas do livro estão divididas em dez capítulos, além da Introdução. Os capítulos foram subdivididos, no geral, em quatro partes: um tema, exercícios, problemas e comentários. Os temas que dão nome aos capítulos são: Os axiomas de incidência e ordem; Axiomas sobre medição de seguimentos; Axiomas sobre medição de ângulos; Congruência; O teorema do ângulo externo e suas consequências; O axioma das paralelas; Semelhança de triângulos; O círculo; Funções trigonométricas; e Área. Não há, todavia, referências bibliográficas.

$\mathrm{Na}$ Introdução o autor ratifica que o livro foi pensado para uma disciplina de Geometria em cursos de licenciatura em Matemática e que a obra só não contempla tópicos relativos ao movimento de figuras e construções com régua e compasso, porque eles apareceriam em versões futuras. Entretanto, esses assuntos foram tratados em livros próprios, publicados por outros autores nesta Coleção da SBM. Em seguida afirma-se que os axiomas adotados na obra "são aqueles selecionados por A. V. Pogorélov em seu livro Geometria Elemental (...) [pois] têm a vantagem de levar o aluno mais rapidamente aos teoremas mais importantes da Geometria Plana" (Barbosa, 1985, p. i).

Ainda na Introdução, ao mencionar que o postulado das paralelas foi deixado apenas para o sexto capítulo, o autor apresenta para o leitor a possibilidade de geometrias não euclidianas. Em relação ao modo como os capítulos foram divididos, Barbosa explica que "os problemas complementam a teoria e têm um caráter mais conceitual, enquanto que os exercícios se destinam mais à fixação do conteúdo apresentado" (1985, p. ii). Os comentários, por sua vez, são uma seleção de tópicos que, apesar de não fazerem parte do conteúdo do livro, eram de grande utilidade na formação dos alunos dos cursos que ele vinha ministrando e que, incentivados por aqueles alunos, decidiu incluí-los no livro.

A parte de conteúdo de cada capítulo encontra-se distribuída segundo um sequenciamento comum para definições, teoremas, proposições e observações. Os axiomas, por outro lado, estão indexados de forma parecida com a proposta de David Hilbert na clássica obra Fundamentos de Geometria, mas são distintos em relação a alguns "tipos" e à sua quantidade. No primeiro capítulo, por exemplo, em que são apresentados dois axiomas de incidência e três de ordem, temos:

AXIOMA $I_{1}$ - Qualquer que seja a reta existem pontos que pertencem a reta e pontos que não pertencem a reta.

AXIOMA $\mathrm{I}_{2}$ - Dados dois pontos distintos exite um única reta que contém estes pontos. (Barbosa, 1985, p. 1, negritos do autor)

(...)

AXIOMA $\mathrm{II}_{1}$ - Dados três pontos de uma reta, um e apenas um deles localiza-se entre os outros dois. (Idem, p. 3, negritos do autor)

\section{(...)}

AXIOMA $\mathrm{II}_{2}$ - Dados dois pontos A e B sempre exitem: um ponto $\mathrm{C}$ entre $\mathrm{A}$ e $\mathrm{B}$ e um ponto $D$ tal que B está entre A e D. (Idem, p. 5, negritos do autor) 


\section{(...)}

AXIOMA $\mathrm{II}_{3}$ - Uma reta $\mathbf{m}$ determina exatamente dois semi-planos distintos cuja interseção é a reta m. (Idem, p. 6, negritos do autor) ${ }^{12}$

Os únicos elementos não definidos são ponto, reta e plano, enquanto todos os demais (seguimento, semirreta, semiplano etc.) são definidos a partir daqueles. A indexação de definições, a propósito, tal como as de proposições e teoremas, é dada primeiramente pelo número do capítulo e a ordem em que aparecem ali. No capítulo segundo, por exemplo, são apresentados, após os axiomas de medição de segmentos (III1 e III2), a proposição 2.1; o teorema 2.2; a definição 2.3; o teorema 2.4; a observação 2.5 e a definição 2.6. Todos os axiomas são escritos com letras negritadas e as definições apresentam apenas as palavras referentes aos conceitos principais em negrito. Outro aspecto relativo à parte gráfica a se destacar são as figuras. Elas servem para determinar um exercício, exemplificar uma definição ou explicação do autor ou dar suporte a uma demonstração. São simples, mas apresentam variação de traços (finos, grossos, tracejados), hachurados e sombreamentos e são numeradas de acordo com a ordem em que aparecem na parte de conteúdo de cada capítulo elas não são indexadas quando aparecem junto a exercícios e problemas.

Para o professor João Lucas, em relação à parte técnica de produção do livro, as figuras representaram uma preocupação. $\mathrm{O}$ texto foi, primeiramente, escrito à mão e, logo em seguida, digitado usando o programa de computador LaTex. Mas as figuras representavam uma dificuldade porque "não era nada fácil colocar uma figura em um texto LaTex" /.../ [elas] ficavam feias, os traços eram muito grossos, não havia diferença entre traços como eu gostaria". Mas esses problemas foram superados com a ajuda de alguns colegas que passaram a manipular melhor aquele software.

No total são apresentadas, geralmente com comentários do autor, 21 definições, 46 proposições, 22 teoremas e nove corolários na parte de conteúdo. Destes, não são apresentadas as demonstrações de sete proposições, parte de uma oitava e quatro corolários que, segundo o autor, têm demonstração simples e ficam como exercício para o leitor. Não há uma diferenciação, pelo autor, sobre os tipos de proposições, mas até pelo que foi dito na Introdução, ficam reservados para a categoria "teorema" os resultados mais significativos, enquanto proposições e corolários são afirmações menos abrangentes.

Com 128 exercícios e 97 problemas estão distribuídos de maneira não uniforme entre os dez capítulos. João Lucas recebeu de professores de outras instituições do Brasil o pedido para incluir mais exercícios. Segundo ele, esses professores tinham dificuldade de produzir novos exercícios para seus cursos. Mas, ainda conforme as palavras de João Lucas, de modo geral, a recepção ao livro foi positiva: no próprio Instituto de Matemática da UFC, os colegas que o substituíram, lecionando a disciplina de Geometria, elogiavam o texto. Alguns teriam

\footnotetext{
12 Os demais axiomas em Barbosa (1985) são os de medição de segmentos e de ângulos (cinco), o axioma das paralelas (único) e axiomas de área (quatro).
} 
DOI: $10.20396 /$ zet.v27i0.8654251

dito que era um "livro difícil" e traziam outros livros para complementar a bibliografia da disciplina. Professores de outras universidades enviaram cartas sugerindo mudanças no texto, pedindo a solução de alguns exercícios/problemas, ou ainda, o que foi bastante comum, enviando correções para serem incluídas nas edições posteriores.

Os comentários que encerram cada capítulo são, em sua maioria, notas históricas que tratam, por exemplo, do desenvolvimento da Geometria Euclidiana, sobre a obra Os Elementos, de Euclides, sobre o Teorema de Pitágoras, a descoberta dos números irracionais e o cálculo do comprimento de uma circunferência pela aproximação do perímetro por polígonos inscritos. Destacamos os comentários que encerram os capítulos 1, 2 e 5 . No primeiro deles, Barbosa (1985) usa uma metáfora para explicar como deve ser entendida a Geometria dizendo que um pai, para ensinar seu filho a jogar damas, por exemplo, mostra o tabuleiro, indica onde posicionar as peças, como movimentá-las e os objetivos de cada jogador. Se o filho decidir perguntar por que se joga daquela maneira e não de outra, a resposta seria simples:

\footnotetext{
Porque esta é uma das regras do jogo. Se alguma delas for alterada, o jogo resultante, embora possa ser também muito interessante, não será mais um jogo de damas. /.../ O importante são as regras do jogo /.../. Qualquer criança, após dominar o jogo, improvisará tabuleiros com riscos no chão e utilizará tampinhas de garrafa, botões, cartões, etc., como pedras. (Idem, p. $10)$.

Geometria, como qualquer sistema dedutivo, é muito parecido com um jogo: partimos um certo conjunto de elementos (ponto, reta e plano) e é necessário aceitar algumas regras básicas sobre as relações que satisfazem esses elementos, as quais são chamadas de axiomas. O objetivo final deste jogo é o de determinar as propriedades características das figuras planas e dos sólidos no espaço. Tais propriedades, chamadas Teoremas ou Postulados, devem ser deduzidas somente através do raciocínio lógico a partir dos axiomas fixados ou a partir de outras propriedades já estabelecidas. (Idem, p. 11).
}

No comentário do final do segundo capítulo o autor aponta que o livro de Euclides, Os Elementos, compila o conhecimento humano de Geometria até a época de sua redação e que a Geometria naquela obra "foi o primeiro sistema de ideias desenvolvido pelo homem, no qual umas poucas afirmações simples são admitidas sem demonstração e então utilizadas para provar outras mais complexas. Um tal sistema é chamado dedutivo". (Barbosa, 1985, p. 22). Páginas mais tarde, ao final do quinto capítulo, Barbosa se dedica a dar mais explicações ao leitor sobre lógica dedutiva, tratando mais formalmente da demonstração de proposições, da resolução de exercícios e da compreensão do enunciado de teoremas. Em cinco páginas o autor dá explicações, com exemplos, sobre o que são hipótese, tese, proposições diretas e inversas, proposições do tipo "se..., então...” e negativa de uma proposição.

\section{Os exercícios/problemas apresentados na obra}

$\mathrm{Na}$ Introdução, quando explica como os capítulos foram divididos, Barbosa (1986) explica o modo como ele diferencia problemas de exercícios, considerando que aqueles "complementam a teoria e têm um caráter mais conceitual, enquanto que os exercícios se 
DOI: $10.20396 /$ zet.v27i0.8654251

destinam mais à fixação do conteúdo apresentado" (1985, p. ii). Segundo essa distinção proposta pelo autor, 128 exercícios e 97 problemas compõem os dez capítulos.

João Lucas Marques Barbosa nos indicou, em contato por e-mail, que que recebeu de professores de instituições de todo o Brasil o pedido para incluir mais exercícios na obra. Segundo ele, a justificativa do pedido era que esses professores tinham dificuldade de produzir novos exercícios para seus cursos. Entretanto, ele também apontou que, de modo geral, a recepção ao livro foi positiva: no próprio Instituto de Matemática da Universidade Federal do Ceará (onde trabalhava à época), os colegas que o substituíram, lecionando a disciplina de Geometria em cursos de graduaçãa, elogiavam o texto. Alguns teriam dito que aquele era um "livro difícil" e levavam às suas aulas outros livros para complementar a bibliografia da disciplina. Professores de outras universidades também escreveram cartas sugerindo mudanças no texto, pedindo a solução de alguns exercícios/problemas, ou ainda, o que ficou muito comum, enviando correções para serem incluídas nas edições posteriores.

O quadro a seguir apresenta a contagem realizada e alguns exemplos de cada categoria de tarefa conforme a tipologia que utilizamos.

Quadro 1 - Classificação das tarefas na obra Geometria Euclidiana Plana

\begin{tabular}{|c|c|c|c|c|}
\hline Categoria & $\begin{array}{l}\text { Frequência } \\
\text { Absoluta }\end{array}$ & $\begin{array}{l}\text { Frequência } \\
\text { Relativa }\end{array}$ & \multicolumn{2}{|c|}{ Exemplos $^{13}$} \\
\hline Exercício & 20 & $8,9 \%$ & $\begin{array}{l}\text { 7e1: Quanto mede a } \\
\text { hipotenusa de um triângulo } \\
\text { retângulo em que os catetos } \\
\text { medem um centímetro cada? }\end{array}$ & $\begin{array}{l}\text { 9e2: Uma árvore de } 10 \text { metros } \\
\text { de altura projeta uma sombra de } \\
12 \text { metros. Qual é a altura } \\
\text { angular do sol? }\end{array}$ \\
\hline Problema & 28 & $12,4 \%$ & $\begin{array}{l}\text { 1e11: Três pontos não } \\
\text { colineares determinam três } \\
\text { retas. Quantas retas são } \\
\text { determinadas por quatro } \\
\text { pontos sendo que quaisquer } \\
\text { três deles não são colineares? }\end{array}$ & $\begin{array}{l}\text { 8e24: Dado um quadrado de } \\
\text { lado } 5 \mathrm{~cm} \text {, qual o raio do círculo } \\
\text { ao qual ele está inscrito? Qual o } \\
\text { raio do círculo que ele } \\
\text { circunscreve? }\end{array}$ \\
\hline $\begin{array}{l}\text { Prova de } \\
\text { conjectura }\end{array}$ & 147 & $65,3 \%$ & $\begin{array}{l}\text { 1p2: Prove que se uma reta } \\
\text { intercepta um lado de um } \\
\text { triângulo e não passa por } \\
\text { nenhum de seus vértices, } \\
\text { então ela intercepta também } \\
\text { um dos outros dois lados. }\end{array}$ & 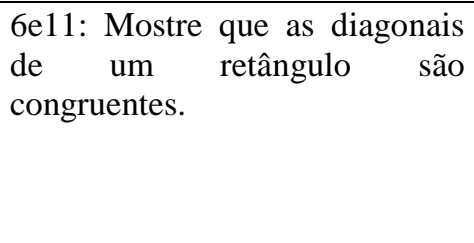 \\
\hline Situação & 11 & $4,9 \%$ & $\begin{array}{l}\text { 1p1: Discuta a seguinte } \\
\text { questão utilizando apenas os } \\
\text { conhecimentos geométricos } \\
\text { estabelecidos, até agora, } \\
\text { nestas notas: "Existem retas } \\
\text { que não se interceptam?" }\end{array}$ & $\begin{array}{l}\text { 4p13: Num triângulo isósceles } \\
\text { ABC, com base BC, a bissetriz } \\
\text { do ângulo Â é perpendicular à } \\
\text { base e é mediana. }\end{array}$ \\
\hline
\end{tabular}

\footnotetext{
${ }^{13}$ Para nosso controle indexamos as atividades propostas no formato $C x N$ em que $\mathrm{C}$ é o número do capítulo onde está a atividade, $\mathrm{x}$ representa em que lista aparece - de exercícios (e) ou de problemas (p) - e $N$ indica a sua numeração naquela lista.
} 
DOI: $10.20396 /$ zet.v27i0.8654251

\begin{tabular}{|l|l|l|l|l|}
\hline Construções & 19 & $8,4 \%$ & $\begin{array}{l}\text { 5p8: Determine o seguimento } \\
\text { mais curto ligando um ponto } \\
\text { A a um ponto de uma reta m. }\end{array}$ & $\begin{array}{l}\text { 8e23: Desenhe dois exemplos } \\
\text { de polígonos equiláteros que } \\
\text { circunscrevem um círculo, mas } \\
\text { que não são regulares. }\end{array}$ \\
\hline Total & 225 & & & \\
\hline
\end{tabular}

Fonte: Elaborado pelo autor.

Embora alguns tipos de tarefas pudessem ser enquadradas em mais de uma categoria o que também é possível usando outras tipologias -, não identificamos tarefas classificadas como puzzles. Destaca-se, por outro lado, a quantidade de tarefas dedicadas à prova de conjecturas (147 das 225). Essa aproximação axiomática da Geometria foi exposta ao leitor daquele livro didático na apresentação feita pela Sociedade Brasileira de Matemática (SBM) em suas primeiras páginas e, como vimos anteriormente, replicada na contracapa, Ela indicava que o objetivo da obra era dar ao futuro professor da educação básica uma visão mais ampla daquilo que ele iria ensinar (Barbosa, 1985, n.p.), mas isso não significava que o futuro professor não adotasse a mesma abordagem quando fosse ensinar.

As justificativas do autor para essa abordagem aparecem em diferentes momentos na obra. Na seção Comentários do primeiro capítulo, Barbosa (1985) usa uma metáfora para explicar como a Geometria deve ser entendida. Dizia ele que se um pai quisesse ensinar seu filho a jogar damas, mostraria o tabuleiro, indica onde posicionar as peças, como movimentálas e os objetivos de cada jogador. Se o filho perguntasse por que se joga daquela maneira e não de outra, a resposta, segundo o autor, seria simples:

Porque esta é uma das regras do jogo. Se alguma delas for alterada, o jogo resultante, embora possa ser também muito interessante, não será mais um jogo de damas. /.../ O importante são as regras do jogo /.../. Qualquer criança, após dominar o jogo, improvisará tabuleiros com riscos no chão e utilizará tampinhas de garrafa, botões, cartões, etc., como pedras. (p. 10).

Geometria, como qualquer sistema dedutivo, é muito parecido com um jogo: partimos com um certo conjunto de elementos (ponto, reta e plano) e é necessário aceitar algumas regras básicas sobre as relações que satisfazem esses elementos, as quais são chamadas de axiomas. O objetivo final deste jogo é o de determinar as propriedades características das figuras planas e dos sólidos no espaço. Tais propriedades, chamadas Teoremas ou Postulados, devem ser deduzidas somente através do raciocínio lógico a partir dos axiomas fixados ou a partir de outras propriedades já estabelecidas. (p. 11).

Em outro Comentário, presente ao final do segundo capítulo, o autor explica que, o famoso livro de Euclides, "Os Elementos", compilam o conhecimento humano de Geometria até a época de sua redação e que a Geometria naquela obra "foi o primeiro sistema de idéias desenvolvido pelo homem, no qual umas poucas afirmações simples são admitidas sem demonstração e então utilizadas para provar outras mais complexas. Um tal sistema é chamado dedutivo". (Barbosa, 1985, p. 22). Páginas mais adiante, no final do quinto capítulo, o autor se dedica a mais comentários ao leitor sobre lógica dedutiva tratando de explicar como fazer a demonstração de proposições, a resolução de exercícios e de como o leitor poderia compreender o enunciado de teoremas. Nesta parte, em cinco páginas Barbosa dá explicações, com exemplos, sobre o que são hipótese, tese, proposições diretas e inversas, 
DOI: 10.20396/zet.v27i0.8654251

proposições do tipo "se..., então..." e negativa de uma proposição. Entretanto neste trecho não são exploradas situações como a de "condições necessárias e suficientes" que não costuma ser óbvia para os estudantes.

Segundo Ferreira e Almouloud (2017) a diferença entre prova (a explicação aceita por certo grupo de pessoas em dado momento que pode ser objeto de um debate voltado a determinar critérios de validação comuns aos interlocutores) e demonstração (um tipo de prova predominante em matemática, pautada por uma série de enunciados que se organizam segundo um conjunto bem definido de regras) implica aceitar outras produções de alunos para estabelecer a validade de uma afirmação. No entanto, o fato de aceitar outras formas de provas produzidas pelos alunos não minimiza, alertam aqueles autores, a importância do papel da demonstração para o ensino da matemática, pois não se pode aprender matemática sem demonstração.

Mesmo assim, podemos supor que o estudante, ao dedicar-se à Geometria proposta pelo livro, especialmente na resolução das tarefas propostas, deveria aprender o que é o método dedutivo e como fazer uma demonstração em matemática enquanto fazia suas tarefas ou acompanhava pelo livro ou pelas aulas de seus professores o estudo dos teoremas apresentados. Um exemplo disso é que só no primeiro capítulo, composto por 20 tarefas, 12 foram classificadas, por nós, como prova de uma conjectura. Há, por outro lado, pouquíssimas atividades que classificamos como Situações (11 entre as 225 propostas), em que determinado conceito pode ser explorado em contextos reais ou hipotéticos e, a partir daí, levar o aluno a fazer conjecturas que o levariam a afirmações que poderiam ser provadas ou refutadas. A preferência, no decorrer da obra, é pela formalização seguida da resolução de alguns problemas ou da demonstração de propriedades ou de conjecturas pré-estabelecidas.

Desse modo, percebe-se uma valorização do conhecimento matemático como uma elaboração estritamente mental, sustentada na dedução lógica. Tal valorização materializa-se na grande quantidade de tarefas com essas características, quanto pela organização do conteúdo sequenciado em definições, teoremas, proposições e observações.

Por sua vez, os conjuntos de axiomas que estruturam a obra e são explorados em diferentes capítulos foram escolhidos de forma parecida com os propostas por David Hilbert na clássica obra "Fundamentos de Geometria".

Uma explicações pelas preferências do autor do livro analisado na escolha da abordagem dos conteúdos e das tarefas propostas em sua obra - para além das óbvias ligações com as já citadas obras de Euclides e Hilbert - podem repousar no fato de que o livro foi lançado na década de 1980 que sucedeu o auge do Movimento da Matemática Moderna no Brasil, ocorrido entre aos anos 1960 e 1970. Esse movimento, de amplitude internacional, impactou, por aqui, desde a produção de livros didáticos para a escola básica até a elaboração de programas de formação continuada de professores. As principais características do ensino que resultaram desse momento eram, de acordo com estudos como 
DOI: $10.20396 /$ zet.v27i0.8654251

o de Miorim (1998), o elevado grau de generalidade, abstração e rigor lógico e a ênfase nas estruturas matemáticas e na axiomatização. Ainda segundo Miorim (1998), o MMM também acabou por levar a matemática escolar a um distanciamento de problemas práticos e ao uso da Teoria dos Conjuntos como elemento responsável pela unificação dos conteúdos, dada sua precisão e linguagem universal.

Dessa forma, o excesso de formalismo nas tarefas propostas na obra estudada, nos parece ligado à sobrevalorização que o formalismo teve no ensino de matemática brasileiro nas décadas de 1960 e 1970.

\section{Considerações finais}

Em qualquer investigação historiográfica as circunstâncias e objetivos definem os parâmetros das análises que serão desenvolvidas sobre suas fontes. Aliás, Bloch (2001) já dizia que a História deve ser problematizadora, ou seja, e construída a partir de perguntas que são feitas no presente. Os vestígios do passado podem se tornar um documento, desde que o historiador saiba colocar as perguntas corretas. Em resumo, ele (o historiador) poderá dar significado ao documento a partir de uma perspectiva que podemos chamar históriaproblema.

Ao nos valermos da HP lidamos com uma análise do objeto de estudo em si e decidimos que o apoio da classificação de problemas, envolvesse uma avaliação tanto quantitativa quanto qualitativa, permitiu apontar a partir da ênfase na seleção dos conteúdos, na sua organização na obra e na proposição de tarefas, uma concepção de formalista de matemática. Segundo Fiorentini (1995) essa concepção caracteriza-se pelo realce nas estruturas matemáticas - neste caso, no modelo geométrico euclidiano. Nessa perspectiva, o conhecimento matemático parte do sujeito, podendo até ser produzido isoladamente do mundo: uma elaboração estritamente mental, levada a cabo por deduções ou por indução lógica (Ibidem).

$\mathrm{Na}$ apresentação do livro, feita pela SBM, chama o abandono da Geometria de nas escolas de "falha" e aponta o livro analisado como "um esforço muito promissor e muito oportuno no sentido de contribuir para corrigir a referida falha no ensino de Matemática em nosso país”. Entretanto, em Barbosa (1995), a sequenciação axioma-definição-teoremademonstração-exercícios, que só era interrompida por pequenas inserções com informações históricas ao final de cada capítulo, apontam a um caráter formativo exclusivamente formalista, sem permitir que os futuros estabelecessem relações e problematizações com a matemática escolar numa perspectiva didático-pedagógica. Conforme apontam Fiorentini e Oliveira (2013), o lugar da matemática nessa concepção de formação docente é central e fundamental, considerando que resta ao professor a aplicação daqueles conhecimentos por um processo de racionalidade técnica e/ou de transposição didática de um saber sábio ou científico para o saber a ser ensinado e, finalmente, em objeto de ensino. 
DOI: $10.20396 /$ zet.v27i0.8654251

Esta análise nos permitiu, também, compreender diferenças entre os currículos idealizados para os professores da educação básica que vem tendo dificuldades em implementar um ensino de Geometria que valorize atividades experimentais e problemáticas que permitam a construção dos conceitos que poderão ser utilizados em outros momentos no decorrer de sua aprendizagem.

\section{Referências}

Barbosa, J. L. M. (1985) Geometria Euclidiana Plana. Rio de Janeiro: SBM.

Borasi, R. (1986) On the nature of problems. Educational Studies in Mathematics, 17(2), 125-141.

Conejo, L. \& Ortega, T. (2013) Clasificación de los problemas propuestos en aulas de Educación Secundaria Obligatoria. Educación Matemática, 25(3), 129-158;

Crescenti, E. P. (2005) Os professores de matemática e a geometria: opiniões sobre a área e seu ensino. Tese de Doutorado em Educação. São Carlos: Universidade Federal de São Carlos.

Dante, L. R. (1988) Criatividade e resolução de problemas na prática educativa matemática. Tese de Livre Docência em Educação Matemática. Rio Claro: Universidade Estadual Paulista.

Duarte, A. R. S. \& Silva, M. C. L. (2006) Abaixo Euclides e Acima Quem? Uma análise do ensino de Geometria nas teses e dissertações sobre o Movimento da Matemática Moderna no Brasil. Práxis Educativa, 1(1), 87-93.

Ferreira, M. B. C. \& Almouloud, S. (2017). Análise dos livros de geometria indicados nos cursos de licenciatura em matemática. REVEMAT, 12(2), 16-57.

Fiorentini, D \& Oliveira, A. T. C. C. (2013) O Lugar das Matemáticas na Licenciatura em Matemática: que matemáticas e que práticas formativas? Bolema, 27(47), 917-938.

Fiorentini, D. (1995) Alguns Modos de Ver e Conceber o Ensino de Matemática no Brasil. Zetetiké, 3(4), 1-37.

Garnica, A. V. M. \& Salandim, M. E. M. (Org.) (2014) Livros, leis, leituras e leitores: exercícios de interpretação para a história da educação matemática. Curitiba: Appris.

Hilbert, D. (2003) Fundamentos da Geometria. Lisboa: Gradiva.

Junqueira, S. M. S. \& Manrique, A. L. (2015) Reformas curriculares em cursos de licenciatura de Matemática: intenções necessárias e insuficientes. Ciência \& Educação, 21(3), 623-635.

Marmolejo, G. A. (2014). Desarrollo de la visualización a través del área de superficies planas. Análisis de libros de texto colombianos y españoles. Tese de Doutorado em Educação. Salamanca: Universidade de Salamanca.

Miorim, M. A. (1988) Introdução à História da Educação Matemática. São Paulo: Atual. 
DOI: 10.20396/zet.v27i0.8654251

Oliveira, F. D. (2008) Análise de textos didáticos: três estudos. Dissertação de Mestrado em Educação Matemática. Rio Claro: Universidade Estadual Paulista.

Pavanello, R. M. (1993). O abandono do ensino da Geometria no Brasil: causas e consequências. Zetetiké, 1(1), 7-17.

Pinos Ceballos, J. (2015) Tipos de Problemas de Matemáticas. In Blanco Nieto, Lorenzo J.;

Cárdenas Lizarazo, Janeth A.; Caballero Carrasco, A. (Eds.). La Resolución de

Problemas de Matemáticas en la Formación Inicial de Profesores de Primaria. (pp 187-

208) Cáceres: Universidad de Extremadura.

Pinto, N. B. (2006) Práticas Escolares do Movimento da Matemática Moderna. Anais do VI Congresso Luso-Brasileiro de História da Educação (pp. 4057-4068). Uberlândia: Universidade Federal de Uberlândia.

Pogorélov, A. V. (1974) Geometría Elemental. Moscou: Mir Moscú.

Rodrigues, M. U.; Silva, L. D. \& Ferreira, N. C. (2016) Clássicos da Educação Matemática nos cursos de Licenciatura em Matemática no Brasil. In D’Ambrosio, B. \& Miarka, R. (Org.). Clássicos na educação matemática brasileira: múltiplos olhares. (pp. 301-346) Campinas: Mercado de Letras.

Santos, V. O. (2016) Uma história da Sociedade Brasileira de Matemática durante o período de 1969 a 1989: criação e desenvolvimento. Tese de Doutorado em Educação Matemática. Rio Claro: Universidade Estadual Paulista.

Schubring, G. (2003) Análise histórica de livros de matemática. Campinas: Autores Associados.

Sierra Vázquez, M., González Astudillo, M. T., López, C. (1999) Evolución Histórica del Concepto de Límite Funcional en los Libros de Texto de Bachillerato y Curso de Orientación Universitaria: 1940-1995. Enseñanza de las Ciencias, 17(3), 463-476.

Silva, J. J. (1999) Filosofia da Matemática e Filosofia da Educação Matemática. In: Bicudo, M. A. V. (Org.). Pesquisa em educação Matemática: Concepções e Perspectivas. (pp. 45-58) São Paulo: Edunesp.

Souza, L. A. \& Cury, F. G. (2015) A Hermenêutica de Profundidade como recurso metodológico para as pesquisas em História da Educação Matemática. Perspectivas da Educação Matemática, 8(18), 5-20.

Thompson, J. B. (2011) Ideologia e Cultura Moderna: teoria social crítica na era dos meios de comunicação de massa. Petrópolis: Vozes.

Valente, W. R. (2008) Livro didático e educação matemática: uma história inseparável. Zetetiké. 16(30), 139-161.

Vidal, D. G. \& Faria Filho, L. M. (2005) As Lentes da História: estudos de história e historiografia da educação no Brasil. Campinas: Autores Associados. 